\title{
GEBAUTE UNANIMITAS. ZU DEN BAUVORSCHRIFTEN DER ZISTERZIENSER
}

\section{Matthias Untermann (Freiburg i.Br.)}

Die mittelalterliche Architektur der Zisterzienser ${ }^{1}$ gilt wegen ihrer eigentümlichen, über Zeiten und Räume hinweg faßbaren Einheitlichkeit als Ergebnis der ebenso bemerkenswerten zentralisierten Ordensorganisation. Lange noch in Denkmustern des 19. Jahrhunderts gefangen, konnten sich Kunstgeschichte und interessiertes Publikum eine solche Einheitlichkeit nur als Ergebnis einer straffen Gesetzgebung vorstellen, die der immer vordrängenden Individualität von Bauherren, Stiftern und Architekten die Zügel angelegt habe. Schon die ersten kunsthistorischen Bemühungen um Zisterzienserarchitektur, die Werke von Joseph Potter, Albert Lenoir und Carl Schnaase, zwischen 1847 und 1856 erschienen, würdigen Kirchen und Klausurgebäude nicht als künstlerische Zeugnisse des Mittelalters, sonders als authentische Belege für eine klösterliche Ordnung und eine strenge Ordensgesetzgebung. ${ }^{2}$ Der systematischen kunsthistorischen Erforschung ging 1877/78 die Publikation der Statuten und Filiationstabellen voraus. ${ }^{3}$ Die Existenz zisterziensischer Bauvorschriften wurde in der Folgezeit von der kunst- und architekturhistorischen Forschung als Tatsache dargestellt - erst 1911 und 1913 sind die regelmäßig zitierten Schriftquellen im Zusammenhang untersucht worden. ${ }^{4}$

1 Die folgenden Ausführungen gründen auf meiner Freiburger Habilitationsschrift „Forma Ordinis. Studien zur mittelalterlichen Baukunst der Zisterzienser", die sich in Druckvorbereitung befindet. Der Vortragstext wurde deshalb nur gering überarbeitet und mit den wichtigsten Nachweisen versehen.

2 Joseph Potter, Remains of ancient monastic architecture in England. London 1847-51; Albert Lenoir, L'architecture monastique, Bd. 1. Paris 1852; Carl Schnaase, Geschichte der bildenden Künste, Bd. 5: Entstehung und Ausbildung des gothischen Styls. Düsseldorf 1856, S. 408-440.

3 Leopold Janauschek, Origines cistercienses, Bd. 1. Wien 1877 (Bd. 2 nicht erschienen); Philippe Guignard, Les monuments primitifs de la règle cistercienne. Dijon 1878.

4 Hermann Rüttimann, Der Bau- und Kunstbetrieb der Cistercienser unter dem Einflusse der Ordensgesetzgebung, in: Cistercienser-Chronik 23 (1911), S. 1-13, 50-57, 69-88, 100-114; Josef Saur, Der Cistercienserorden und die deutsche Kunst des Mittelalters, besonders in Hinsicht auf die Generalkapitelsverordnungen, in: Studien und Mitteilungen zur Geschichte des Benediktinerordens und seiner Zweige 34 (Neue Folge 3) (1913), S. 475-522, 660-699. 
Damals wurde bereits alles wichtige gesagt - wesentliche neue Quellen sind seitdem nicht erschlossen worden, wenn man von der vielbenutzten, aber unzureichenden Edition der Generalkapitelsstatuten durch Canivez absieht. ${ }^{5}$ Seit fast einem Jahrhundert also ist geklärt, daß die Zisterzienser keine eigentlichen Bauvorschriften hatten - sondern nur Verbote, die den Bauluxus betreffen. Die Kunstgeschichte ist mit dieser Feststellung nicht recht glücklich geworden: Es gab Erklärungsbedarf für die eigentümlichen Bauformen des Ordens und deren Verbreitung, wenn man nicht - wie es auch geschah - einen „zisterziensischen Geist“ dafür verantwortlich machen wollte. ${ }^{6}$ Die Behauptung, „es gäbe Bauvorschriften des Ordens", hielt sich deshalb standhaft, nicht zuletzt in Publikationen der Nachbarfächer und in populärwissenschaftlichen Werken. Gegen diese Grundstimmung argumentierten 1987 Schreiber und Köhler in ihrer ebenso nüchternen wie nützlichen Studie zu den "Baugesetzen“ der Zisterzienser. Sie zeigen erneut auf, wie wenig Raum Aussagen zur Architektur in den Statuten des Ordens einnehmen. ${ }^{7}$ Diesem Resultat wäre kaum etwas hinzuzufügen. ${ }^{8}$

Zunächst sollen die bekannten Schriftquellen kurz zusammengefaßt werden - auch wenn dies nicht originäre Aufgabe des Kunsthistorikers sein kann. Er steht mit einigem Unbehagen vor den Quellen, da eine zuverlässige, kritische Edition gerade für die Generalkapitelsbeschlüsse

5 Joseph-Maria Canivez, Statuta capitulorum generalium ordinis Cisterciensis ab anno 1116 ad annum 1786, 8 Bände (Bibliothèque de la Revue d'Histoire Ecclesiastique 9-16). Louvain 1933-41; vgl. dazu die Rezension von G. Rath, in: Cistercienser-Chronik 48 (1936), S. 50-60.

6 Der ältere Forschungsstand wird dominiert von Marcel Aubert, L'architecture cistercienne en France, 2 Bde. Paris 1943 (2. Aufl. 1947); François Bucher, NotreDame de Bonmont und die ersten Zisterzienserabteien der Schweiz (Berner Schriften zur Kunst 7). Bern 1957; Hanno Hahn, Die frühe Kirchenbaukunst der Zisterzienser (Frankfurter Forschungen zur Architekturgeschichte 1). Berlin 1957.

7 Rupert Schreiber / Mathias Köhler, Die „Baugesetze“ der Zisterzienser. Meßkirch 1987.

8 Vgl. an jüngeren Studien zum Thema außerdem: Philippe Dautrey, Simplicité, fille de croissance et de discipline: l'évolution de l'attitude des cisterciens vis-à-vis de leur cadre de vie entre 1180 et 1245, in: Benoît Chauvin ( $\mathrm{Hg}$.), Mélanges à la mémoire du Père Anselme Dimier, Bd. II/3. Arbois 1984, S. 73-91; Jean-Baptiste Auberger, L'unanimité cistercienne primitive, mythe ou réalité? (Cîteaux, Studia et documenta 3). Achel 1986; Conrad Rudolph, The "Principal Founders" and the Early Artistic Legislation, in: Meredith Parsons Lillich (Hg.), Studies in Cistercian Art and Architecture 3 (Cistercian Studies Series 89). Kalamazoo 1987, S. 8-21. 
fehlt. Den Beginn bildet das Exordium, es folgen die normativen Texte und die theologischen Traktate. Danach seien die eigentlich kunsthistorischen Aspekte des Themas angesprochen.

\section{ZISTERZIENSERARCHITEKTUR IM BLICK DES „EXORDIUM PARVUM“}

Schon im „Exordium parvum“, also vor 1119, wird im Sinne zisterziensischer Demut alles verboten (cap. 17), was nach superbia und superfluitas riecht, also nach Hochmut und Überfluß. ${ }^{9}$ Diese Bestimmung ist Grundlage für die gesamte mittelalterliche Baukunst des Ordens und für alle nachfolgenden Einzelentscheidungen des Generalkapitels. Ausdrücklich genannt werden als Elemente der Kirchenausstattung lediglich goldene und silberne Kreuze; erlaubt sind ein bemaltes Holzkreuz, ein Leuchter aus Eisen, Räuchergefäße aus Eisen oder Kupfer, liturgische Gewänder aus grobem Gewebe oder Leinen, obne goldenes oder silbernes Pallium, Altartücher aus Leinen, obne Bilder, die liturgischen Gefäße aus Silber, allenfalls vergoldet. Diese Bestimmung folgt den wenig älteren Consuetudines der Kartäuser $^{10}$ und stellt einen bewußten Bruch dar zur Frühzeit des novum monasterium: Der Klostergründer Robert hatte nämlich die reiche Ausstattung seiner Abtskapelle aus Molesme mitgenommen. ${ }^{11}$ Es ist umstritten und kaum zu klären, ob die Wende zur ausdrücklichen Demonstration von Armut vor oder nach dem Eintritt Bernhards und seiner Gefährten stattfand, also vor oder nach 1113. Gerade die jüngere amerikanische Forschung hat diese Wende mit angeblich neu eingebrachten asketischen Zielen Bernhards verbunden und deshalb nach 1115 datiert. ${ }^{12} \mathrm{Al}-$

9 Jean de la Croix Bouton / Jean-Baptiste van Damme, Les plus anciens textes de Cîteaux (Cîteaux, Studia et documenta 2). Achel 1974 (2. Aufl. 1985), S. 81; François de Place, Cîteaux, Documents primitivs, Texte latin et traduction française. Cîteaux 1988, S. 50. - Vgl. hierzu Rudolph, Principal Founders, in: Lillich (Hg.), Cistercian Art and Architecture, 1987, S. 8-21

10 Guigo von Châtel, Consuetudines Carthusienses c. 41; Edition: M. Laporte $(\mathrm{Hg}$ ), Guigues Ier, Coutumes de Chartreuse (Sources chrétiennes 313; Série des textes monastiques d'Occident 52). Paris 1984, S. 244-245.

11 Vgl. dazu Conrad Rudolph, The „Things of Greater Importance“. Bernard of Clairvaux's Apologia and the Medieval Attitude Toward Art. Philadelphia 1990, S. 187 mit Anm. 506.

12 Rudolph, Principal Founders, in: Lillich (Hg.), Cistercian Art and Architecture, 1987, S. 15 und 29; vgl. zum Datum von Bernhards Eintritt: Adriaan Hendrik Bredero, Études sur la "Vita prima“ de Saint Bernard, in: Analecta Sacri Ordinis Cisterciensis 17 (1961), S. 3-72, 215-260, hier S. 61 mit Anm. 2 und S. 70-72; 
lerdings scheint gerade die nunmehr betonte asketische Strenge die anfangs fehlende Attraktivität von Cîteaux begründet zu haben - und war damit eher ein Argument für den Eintritt so zahlreicher Adliger. Für Bauwesen und Wirtschaftsführung war dieser Beschluß grundlegend: Nun durften überschüssige Einkünfte und Spenden nicht, wie im traditionellen Mönchtum, einem Kirchenschatz oder einer besonders reichen Ausstattung zugute kommen - sie mußten, wie sich zeigt, reinvestiert werden.

Dieses kartäusische und zisterziensische Ausstattungsverbot fand ein sehr unterschiedliches Echo. Abt Suger von St-Denis hebt zwanzig Jahre später, in der Tradition des antiken Architekturlobs, die prachtvolle Ausstattung seiner Abteikirche besonders hervor. ${ }^{13}$ Petrus Abaelard, der Zisterzienserforschung vornehmlich als theologischer Widersacher Bernhards im Bewußtsein, seit etwa 1120 Mönch derselben Abtei, übernimmt 1133 in seine Regel für den Nonnenkonvent der Héloïse in $\mathrm{Pa}$ raclet mit eigenen Worten dieses Verbot von kostbaren Gefäßen, Altartüchern und Skulpturen - wiederum mit Ausnahme eines bemalten Altarkreuzes. ${ }^{14}$

\section{DIE BESCHLÜSSE DER GENERALKAPITEL}

In den Generalkapiteln der Zisterzienser ist das Ausstattungsverbot in der Folgezeit präzisiert und ergänzt worden. ${ }^{15}$ Schon ein vor $1124 / 25$ gefaßter Beschluß verbietet allgemein Skulpturen und Gemälde im Klo-

Ders., Analecta Sacri Ordinis Cisterciensis 18 (1962), S. 3-59; Ders., Saint Bernard est-il né en 1090 ou en 1091? in: Pierre Guichard (Hg.), Papauté, monachisme et théories politiques. Études d'histoire médiévale offerts à Marcel $\mathrm{Pa}$ caut, Bd. 1 (Collection d'histoire et de l'archéologie médiévales 1). Lyon 1994, S. 229-241. - Wilhelm von Malmesbury verband um 1135 die erste Blütezeit von Cîteaux ausschließlich mit dem Namen des Abts Stephan (Gesta Regum Anglorum IV 337; ed. Migne, Patrologia Latina 184, Sp. 1289-1290).

13 Günther Binding / Andreas Speer ( $\mathrm{Hg}$.), Abt Suger von Saint-Denis, De consecratione (56. Veröffentlichung der Abteilung Architekturgeschichte des Kunsthistorischen Instituts der Universität zu Köln). Köln 1995.

14 Terentius P. McLaughlin, Abelard's Rule for Religious Women, in: Mediaeval Studies 18 (1956), S. 241-292, hier S. 263.

15 Zitiert wird die Edition von Canivez, Statuta; beste Zusammenstellung jetzt: Christopher Norton, Table of Cistercian Legislation on Art and Architecture, in: Christopher Norton / David Park ( $\mathrm{Hg}$.), Cistercian Art and Architecture in the British Isles. Cambridge u.a. 1986, S. 315-393. 
ster. ${ }^{16}$ Die um 1149/50 zusammengestellten instituta fügen als Begründung hinzu, daß die Ablenkung durch solche Dinge dem Nutzen einer guten Meditation und der Strenge des monastischen Ernstes schade; damals werden auch farbige Buchstaben in den Handschriften verboten, ebenso wird die Farb- und Bildlosigkeit der Glasfenster vorgeschrieben. ${ }^{17}$ Ältere mehrfarbige Fenster müssen einem Beschluß von 1159 zufolge entfernt werden. ${ }^{18}$ Nur 1157 gibt es mehrere Beschlüsse zum Bauwesen: Die weiße Bemalung der Türen wird erlaubt, steinerne Glockentürme werden verboten, das Gewicht der Glocken wird beschränkt, Stiftergräber sind nun ausdrücklich zugelassen. ${ }^{19}$ Im ersten „Gesetzbuch“ der Zisterzienser, dem „Libellus definitionum“ von 1202 werden genau diese Beschlüsse systematisch zusammengefaßt. ${ }^{20}$ Wenige Jahre später erscheinen dann mehrfarbige Fußböden aus Tonfliesen als Problem - in Pontigny wird im Weihejahr 1205 der Bodenbelag gerügt, weil er levitas ausstrablt und durch seine superfluitas und curiosa varietas (auffällige Mehrfarbigkeit) dem Armutsgebot widerspricht; 1213 wird ein ausdrückliches Verbot solcher Böden erlassen. ${ }^{21}$ Vermutlich ist das Verbot mehrfarbiger Baukeramik aber schon älter. ${ }^{22}$

Zur Architektur selbst gibt es - vom Turmverbot abgesehen - von Seiten des Generalkapitels nur Einzelentscheidungen. Sie sind erst ab 1192 faßbar und betreffen auffallenderweise nur nordfranzösische Klö-

16 Capitula ("von 1123/24“), cap. 25-26: Bouton / van Damme, Anciens textes de Cîteaux, 1974, S. 124-125; de Place, Cîteaux. Documents primitivs, 1988, S. 134135.

17 Instituta, cap. 10, 20, 80: Canivez, Statuta I, S. 15, 17, 31. - Zur umstrittenen Datierung vgl. Neil Stratford, A Romanesque Marble Altar-Frontal in Beaune and Some Cîteaux Manuscripts, in: Alan Borg / Andrew Martindale ( $\mathrm{Hg}$.), The Vanishing Past (British Archaeological Reports, International Series 111). Oxford 1981, S. 223-239, hier S. 227; Rudolph, Principal Founders, in: Lillich (Hg.), Cistercian Art and Architecture, 1987, S. 21-28.

181159 Nr. 9: Canivez, Statuta I, S. 70.

191157 Nr. 12, 16, 21, 63: Canivez, Statuta I, S. 61-62, 68.

20 Bernard Lucet, La codification cistercienne de 1202 et son évolution ulteriéure (Bibliotheca cisterciensis 2). Rom 1964, S. 27-36.

211205 Nr. 10, 1213 Nr. 1, vgl. 1218 Nr. 5 und 1235 Nr. 30: Canivez, Statuta I, S. 308-309, 404, 486, II, S. 146.

22 Vgl. ein undatiertes Statut, das in Vauclair im Kontext mit Beschlüssen von 1157/1182 überliefert ist (tegule variate et vitree tincte et picte auferantur): Jean Leclercq, Épitres d'Alexandre III sur les Cisterciens, in: Revue bénédictine 64 (1954), S. 68-82, hier S. 77-78. 
$\operatorname{ster}^{23}:$ In Longpont muß das neue Dormitorium innerhalb von drei Jahren ad formam ordinis zurückgebaut werden; in Vaucelles hatte der Vaterabt von Clairvaux den Bau der Kirche nicht verhindert, die allzu aufwendig (sumptuose) und unmäßig (superfluus) ist und an der viele Anstoß genommen haben. In Boheries muß 1217 der Glockenturm, der gegen forma und instituta des Ordens gebaut wurde, abgebrochen werden zumindest aber soll das Überflüssige entfernt werden. Bauaufwand und Unmäßigkeit wurden 1227 sogar an einem Grangienbau - also an einem Wirtschaftsgebäude - der Abtei Pontigny gerügt. ${ }^{24}$ Die Verbote aufwendiger Baumaßnahmen bei unsicherer Finanzlage der Klöster stehen in einem anderen Zusammenhang.

Wichtiger als die Aussage, daß im Generalkapitel Architektur und Bauwesen nur am Rande eine Rolle spielen, scheint mir die Beobachtung, daß man sich um 1200 ohne weiteres auf eine forma ordinis beziehen konnte, also auf ordenseigentümliche Bau- und Verhaltensweisen, die freilich nirgends umfassend schriftlich fixiert waren. ${ }^{25}$

Die Formulierung des erneuerten "Libellus definitionum“ von 1237 spiegelt, sich von den älteren Einzelfallentscheidungen ablösend, solche allgemeinen Vorstellungen von forma ordinis. ${ }^{26}$ Gestattet sind hölzerne Türme von mäßiger Höhe, die die simplicitas des Ordens nicht entehren; Skulpturen, Gemälde, Bauten und Fußböden müssen frei sein von superfluitates und curiositates notabiles, also aufsehenerregenden Elementen, die die alte honestas des Ordens entstellen und nicht mit seiner paupertas übereinstimmen.

Die kunstgeschichtliche Forschung zur Zisterzienserarchitektur befindet sich in einer merkwürdig paradoxen Situation: Für die Frühzeit des Ordens fehlen jegliche normative Bauvorschriften - vom erwähnten Turmverbot abgesehen - und dennoch hat gerade die Zisterzienserarchitektur des 12. Jahrhunderts die Forschung am intensivsten beschäftigt

231192 Nr. 23, 31, 1217 Nr. 27, 1218 Nr. 53: Canivez, Statuta I, S. 150-151, 471, 495.

241227 Nr. 34: Canivez, Statuta II, S. 62.

25 Vgl. neben den oben genannten Beschlüssen von 1192 und 1217, Generalkapitelsbeschlüsse zu Stiftergräbern von 1197 Nr. 14, 26 und 1198 Nr. 18: Canivez, Statuta I, S. 212, 215, 225. - Gert Melville, Zur Funktion der Schriftlichkeit im institutionellen Gefüge mittelalterlicher Orden, in: Frühmittelalterliche Studien 25 (1991), S. 391-417, hier S. 403-404; Klaus Schreiner, Verschriftlichung als Faktor monastischer Reform, in: Hagen Keller / Klaus Grubmüller / Nikolaus Staubach (Hg.), Pragmatische Schriftlichkeit im Mittelalter (Münstersche Mittelalter-Schriften 65). München 1992, S. 37-75, hier S. 49-53.

26 Bernard Lucet, Les codifications cisterciennes de 1237 et de 1257. Paris 1977. 
und prägt das allgemeine Bild von Ordensbaukunst viel stärker als die hochgotischen Bauten.

\section{DIE VISITATIONSPROTOKOLLE}

Eine zweite Gattung normativer Quellen sind die Visitationsprotokolle der Vateräbte. Die einzigen für die Architektur aussagekräftigen Protokolle des 13. Jahrhunderts stammen von Stephan Lexington, damals Abt von Savigny, aus den Jahren 1231-33 - sie wurden 1952 publiziert $^{27}$. Er hat einerseits die Einhaltung der Bestimmungen über Malereien, Altarretabel, Fußböden, Glasfenster und Türme, andererseits die korrekte Anordnung der Dormitoriumszellen ${ }^{28}$ angemahnt. Verboten waren schon damals nicht mehr die Zellen selbst, sondern nur noch deren Verschluß durch Türen. Darauf bezog sich wohl auch der Beschluß zu Longpont. Wichtiger ist seine Stellungnahme zu den neuen Kreuzgängen von Beaubec und Barbery sowie zur Kirche von Fontaines-les-Blanches. ${ }^{29}$ In Beaubec sollen die Knollen (nodi), die Hörner (cornua) und die vielen anderen auffalligen Skulpturen ringsum im Kreuzgang entfernt werden; die Vielzabl der Säulen und Rundfenster soll zur simplicitas des Ordens reduziert werden. In Barbery ordnet Stephan an, die Säulen des Kreuzgangs, soweit man das obne Einsturzgefabr machen kann, zur simplicitas des Ordens zurückzuarbeiten, und in Fontaines soll man darauf achten, daß die Kapitelle und andere Werkstücke für den Neubau der Kirche nicht von der simplicitas des Ordens abweichen - hier wird eine deutliche Ablehnung der aktuellen gotischen Baukunst spürbar. Leider sind die drei von Stephan Lexington gerügten Bauten nicht erhalten, aber ein Blick in zisterziensische Kreuzgänge dieser Zeit - zum Beispiel Fontenay oder Noirlac - macht deutlich, was er meint nämlich Knospenkapitelle und Bündelsäulen. Dies zeigt zugleich, daß Stephans Haltung im Orden letztlich nicht geteilt wurde. Dasselbe gilt für den genannten Kirchenbau von Vaucelles, der

27 Bruno Griesser, Registrum epistolarum Stephani de Lexinton abbatis de Stanlegia et de Saviniaco, in: Analecta Sacri Ordinis Cisterciensis 8 (1952), S. 182-378. Der erste Teil des Briefbuchs, ebd. 2 (1946), S. 1-118.

28 Griesser, Registrum (1952), S. 200-201: Coggeshall Nr. 8 und 12; S. 203: Furness Nr. 10; S. 205: Longvillers Nr. 1; S. 206: Beaubec Nr. 1; S. 210-211: Aulnay Nr. 1 und 7; S. 213: St.-André Nr. 1; S. 214: Champagne Nr. 1.

29 Griesser, Registrum (1952), S. 206: Beaubec Nr. 4; S. 208: Fontaines Nr. 1; S. 213 : Barbeau Nr. 6. Vgl. dazu Dautrey, Simplicité, in: Chauvin (Hg.), Mélanges à la mémoire du Père Dimier, 1984, S. 84-85. 


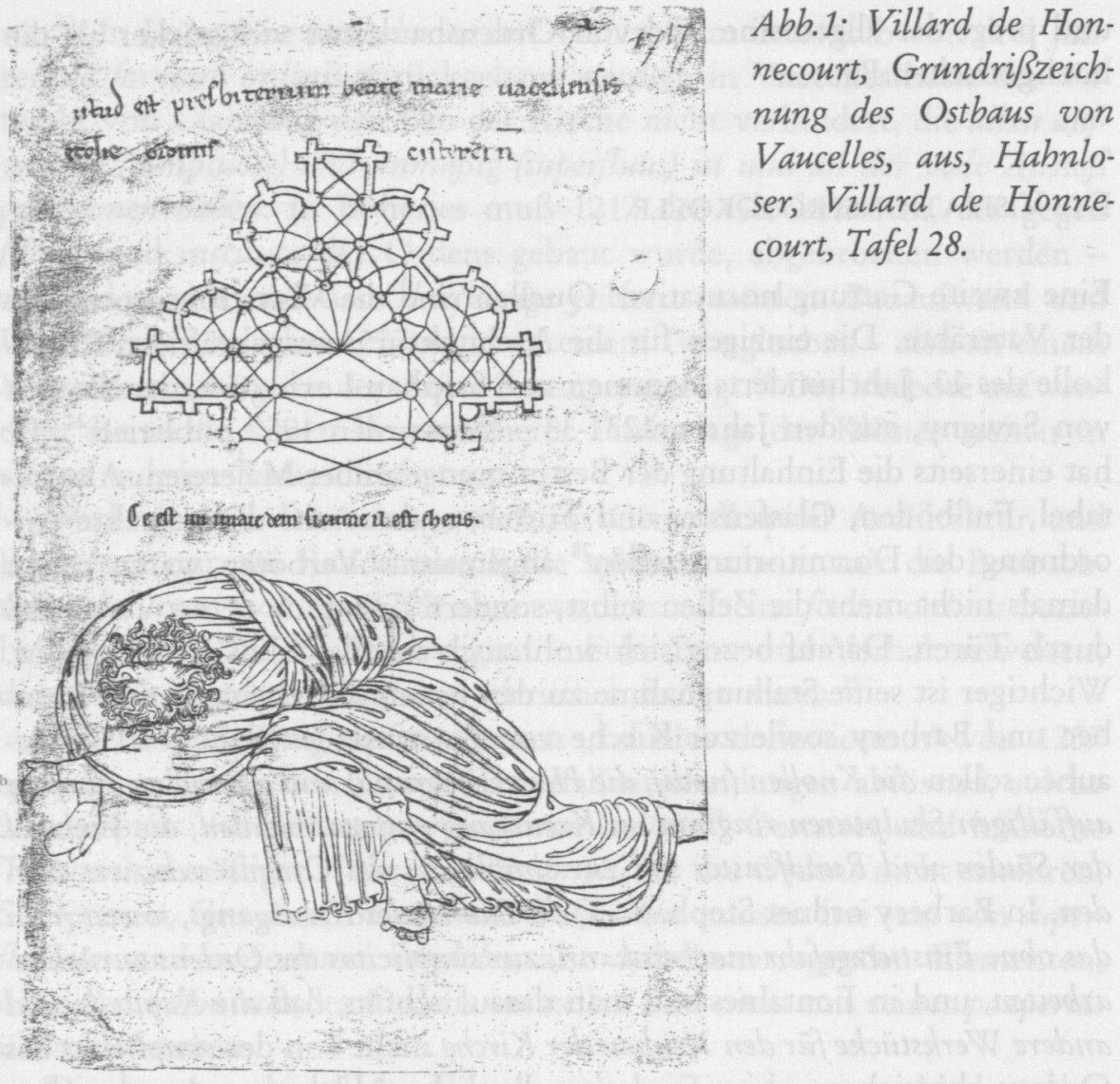

trotz der Kritik des Generalkapitels in aufwendiger Form fertiggestellt wurde. Genau diese Kirche hat Villard de Honnecourt als wichtigen, nordfranzösischen Bau gezeichnet (Abb. 1). ${ }^{30}$

\section{DIE THEOLOGISCHEN TRAKTATE}

Für die Frühzeit des Ordens ist eine dritte Quellengattung heranzuziehen, nämlich die theologischen Traktate. Hierzu gehört an erster Stelle die bekannte Apologie Bernhards von ca. 1124/25 mit seinen, wie man

30 Hans R. Hahnloser, Villard de Honnecourt. Graz 21972, S. 78-79, 230-231, 359, Tafel 33a; ergänzend dazu Wolfgang Schöller, Eine Bemerkung zur Wiedergabe der Abteikirche von Vaucelles durch Villard de Honnecourt, in: Zeitschrift für Kunstgeschichte 41 (1978), S. 317-322. 


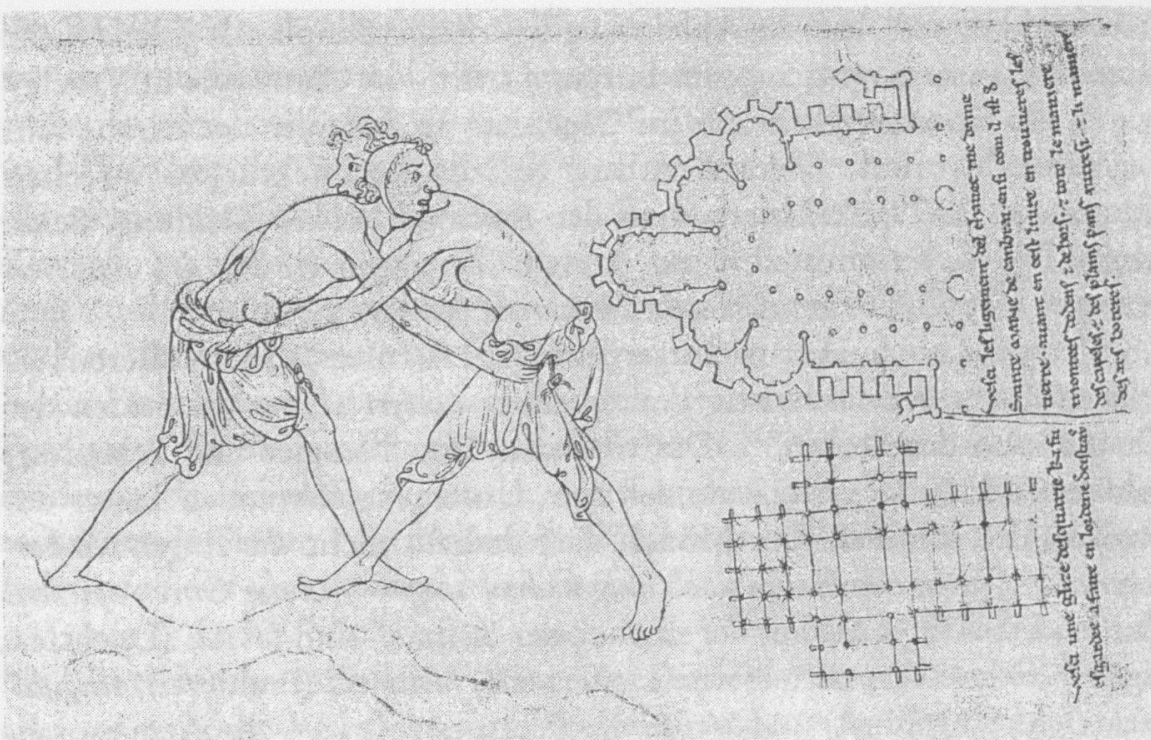

Abb. 2: Villard de Honnecourt, Skizze einer Zisterzienserkirche, aus: Habnloser, Villard de Honnecourt, Tafel 28.

meint, gegen Cluny gerichteten Äußerungen ${ }^{31}:$ Ich übergehe die grenzenlose Höhe der Betbäuser, ihre übermäßige Länge und unnötige Breite, ihre kostspieligen Marmorarbeiten und die staunenerregenden Malereien. Dies alles zieht den Blick der Betenden auf sich und hindert die Andacht. Und wenig später, mit einem Persius-Zitat ${ }^{32}:$ Sagt, ibr Armen, was soll das Gold im Heiligtum? Die oft zitierten Details dieser Schrift bedürfen keiner erneuten Darlegung, auch nicht die gekonnt-satirische Charakterisierung romanischer Kapitellplastik. Es ist längst bekannt, daß dieses Werk topoi der antiken und mittelalterlichen Bauluxus-Kritik benutzt. Zu Recht hat

31 Bernhard von Clairvaux, Apologia ad Guillelmum Abbatum, cap. 28-29: Edition: Jean Leclercq / Henri M. Rochais (Hg.): Sancti Bernardi Opera III: Tractatus et opuscula. Rom 1963, S. 104-106. Wiederabdruck mit deutscher Übersetzung und historischem Kommentar: Gerhard B. Winkler, Bernhard von Clairvaux, Sämtliche Werke II. Innsbruck 1992, S. 192-197. - Vgl. Rudolph, Things of Greater Importance, 1990; Ders., Principal Founders, in: Lillich (Hg.), Cistercian Art and Architecture, 1987; Ders., The Scholarship on Bernard of Clairvaux's Apologia, in: Cîteaux 40 (1989), S. 69-111.

32 Persius, Satyricon II 69. Als Zitat bereits um 1110 verwendet, aber zurückgewiesen von Sigebert von Gembloux, Gesta abbatum Gemblacensium (MGH SS 8, S. 540). 
Stratford betont $\mathrm{t}^{33}$, daß die Ablehnung figürlicher Bauplastik gerade nicht cluniazensische Kreuzgänge im Burgund trifft - in Cluny wie in Vezelay waren die Kreuzgangkapitelle im Gegensatz zu denen in der Kirche rein vegetabil dekoriert. Bevor Bernhard auf die Architektur zu sprechen kommt (c. 28-29), kritisiert er in der Apologie reiche Kleidung. Seine Moral läßt sich unmittelbar auf Bauten übertragen (c. 26): Im Äußeren gezeigter Überflußist ein Anzeichen innerer Leer ${ }^{34}$.

Weniger üblich, aber wichtiger ist es, auf Bernhards kaum älteren, ersten größeren monastischen Traktat hinzuweisen „Über die Stufen der Demut und des Stolzes" ${ }^{335}$. Die curiositas, also Neugier und Schaulust, bildet nämlich die erste Stufe der zum Untergang führenden Leiter des Stolzes, der superbia. Der Mönch darf deshalb nicht die Augen umberscbweifen lassen, das Haupt boch aufgerichtet tragen und die Obren spitzen. Die nächsten fünf Stufen der "Leiter des Stolzes“ sind levitas (Leichtfertigkeit), inepta laetitia (alberne Heiterkeit), iactantia (Prahlerei), singularitas (Ichbezogenheit) und arrogantia (Vermessenheit) - alle diese moralischen Begriffe lassen sich unmittelbar auf künstlerische Werke, auf Bauten und ihre Ausstattung anwenden. Bereits die curiositas gefährdet, wie Bernhard später im „Liber de modo bene vivendi“ ausführt, auctoritas und Gehorsam und führt hin zu Ketzerei und Frevel. ${ }^{36}$

Die Räume monastischer Existenz dürfen also bei den Zisterziensern den Mönch nicht zur Schaulust verführen, wie dies die kritisierten Kirchen und Kreuzgänge der traditionellen Benediktiner tun. Bauweise und Ausstattung dürfen nicht als leichtfertig, prahlerisch, einzigartig oder vermessen erscheinen - und gerade das sind bekanntlich zu allen Zeiten Attribute künstlerischer Höchstleistungen. Basis dieser Forderungen ist

33 Stratford, Cîteaux Manuscripts, in: Borg / Martindale (Hg.), Vanishing Past, 1981, S. 228; vgl. Ders., Les bâtiments de l'abbaye de Cluny à l'époque médiévale: État de questions, in: Bulletin monumental 150 (1992), S. 383-411, hier S. 394, 396-397, auch S. 389-390; Conrad Rudolph, Bernard of Clairvaux's „Apologia“ as a Description of Cluny and the Controversy over Monastic Art, in: Current Studies on Cluny, Gesta 27 (1988), S. 125-133.

34 Bernhard, Apologia c. 26: S. Bernardi Opera II, S. 102; Winkler, Bernhard II, S. 188-189.

35 Bernhard von Clairvaux, De gradibus humilitatis et superbiae; Edition: S. Bernardi Opera III, S. 13-59, hier S. 14, 38-40; Winkler, Bernhard II, S. 29-131, hier S. 40-41, 88-93.

36 Bernhard von Clairvaux, Liber de modo bene vivendi (Unterrichtung für Zisterziensernonnen), c. 59: Migne, PL 184, Sp. 1199-1306, hier Sp. 1280 C. 
die Benediktsregel selbst (cap. 52) ${ }^{37}:$ Das oratorium soll sein, was sein $\mathrm{Na}$ me sagt [ein Bethaus, d.V.] und nichts anderes soll dort getan oder aufbewabrt werden. Schaulust erweckende Bauten widersprechen also Geist und Wortlaut der Benediktsregel, weil sie den Mönch vom Gebet, von der demütigen Aufmerksamkeit im Kapitel und von der Lesung im Kreuzgang ablenken - vor allem aber, weil sie ihn durch curiositas und levitas auf den Irrweg zur superbia verführen können.

Eine letzte Gruppe von Äußerungen sei hier noch angefügt: Bernhards Einschätzung des materiellen Kirchenbaus in seinen KirchweihPredigten. Es überrascht nicht, daß Bernhard die gebaute ecclesia ganz eindeutig der lebendigen ecclesia, der Gemeinschaft der Gläubigen, unterordnet: In Sermo 1 formuliert er: Was könnten diese Steine an Heiligem haben, daß wir ibre Weibe feiern sollten? Und doch sind sie heilig, aber wegen unserer Leiber. ${ }^{38}$ Später hat er sogar die Bezeichnung "Haus Gottes" für Klosterkirchen abgelehnt (Sermo 2): Dieser sichtbare Tempel ist für uns und unsere Wobnung erbaut, denn der Allerböchste (Apg. 17,24) weilt nicht in Tempeln, die von Menschenhand gemacht sind. Was für einen Tempel sollen wir ibm auch bauen, der gesagt hat (Jes. 23,24): Ich bin es, der Himmel und Erde erfüllt.$^{39}$ Freilich ist der Kirchenbau für Bernhard weiterhin ein Ort, wo Gott unter den Mönchen anwesend ist.

37 Basilius Steidle ( $\mathrm{Hg}$.), Die Benediktus-Regel, lateinisch-deutsch. Beuron 4. Aufl. 1980, S. 150-151.

38 Bernhard von Clairvaux, Sermo 1 in dedicatione ecclesiae, Bd. 1: S. Bernardi Opera V (Sermones 2), S. 370.- Vgl. auch Sermo 4, 3 (ebd. S. 385) und 1 Cor. 3,17 .

39 Bernhard von Clairvaux, Sermo 2 in dedicatione ecclesiae: S. Bernardi Opera V, S. 376. Vgl. zu beiden Sermones: Karl Heinz Esser, Über den Kirchenbau des hl. Bernhard von Clairvaux. Eine kunstwissenschaftliche Untersuchung aufgrund der Ausgrabung der romanischen Abteikirche Himmerod (mit Ausgrabungsbericht), in: Archiv für mittelrheinische Kirchengeschichte 5 (1953), S. 195-222, hier S. 205-206; M. Kilian Hufgard, Saint Bernard of Clairvaux. A theory of art formulated from his writings and illustrated in twelfth-century works of art, Diss. 1957, leicht überarb. Druckfassung (Mediaeval Studies 2). Lewiston / Queenston / Lampeter 1989, S. 67-68. 


\section{NICHT „BAUVORSCHRIFTEN“ , SONDERN KRITERIEN FÜR HEILS- WIRKSAME ARCHITEKTUR}

Als "Bauvorschriften“ im engeren Sinn wird man alle diese schriftlich überlieferten Äußerungen zu Architektur und Ausstattung nicht bezeichnen können, dennoch sind sie wesentlich für ein Verständnis der gesamten Zisterzienserbaukunst. Zwei Aspekte sind festzuhalten: Der frühe, bewußte Verzicht auf eine reiche Ausstattung ist ein äußeres Zeichen der paupertas und simplicitas, und zwar sowohl nach außen hin, gegenüber der Umwelt und den Stiftern, als auch nach innen gegenüber dem Konvent. Dies manifestiert sich vornehmlich in den normativen Quellen. Der Verzicht ist zweitens ein Versuch, den Mönch von der Gefährdung durch curiositas zu bewahren und ihm den Fortschritt auf der monastischen Leiter der Demut zu erleichtern. Dies wird in den monastischen Traktaten faßbar, nicht nur bei Bernhard, sondern auch bei anderen Autoren, wie zum Beispiel Aelred von Rievaulx ${ }^{40}$.

Die Suche nach Bauvorschriften des Ordens war von einer kunsthistorischen Beobachtung angeregt, nämlich von der eigentümlichen Einheitlichkeit der Zisterzienserarchitektur, und von der Existenz normativer Quellen scheinbar begünstigt worden, nämlich von den Generalkapitelsbeschlüssen. Sie bleibt aber letztlich vergeblich, und damit folge ich trotz anders gesetzter Akzente dem älteren Forschungsstand. Als Kunsthistoriker kann man mit diesem Ergebnis gleichwohl nicht zufrieden sein - und das ist ja auch eine Ursache dafür, daß das Thema der Bauvorschriften regelmäßig wieder auf der Tagesordnung erscheint. Weiterführend scheint es, schriftliche Überlieferung und Bauten nicht unter der in Denkstrukturen des 19. Jahrhunderts entwickelten Vorstellung von „Bauvorschriften“ zu betrachten, sondern in den Bauten wie in den überlieferten Aussagen zeitgenössische Kriterien für eine in Außen- und Innenwirkung angemessene, „monastisch heilswirksame“ Bauweise zu erkennen.

Dazu sollen noch drei Aspekte kurz angesprochen werden, die den geistigen Hintergrund der Zisterzienserbaukunst erhellen können.

40 Aelred von Rievaulx, Speculum caritatis II 24: Anselm Hoste / Charles H. Talbot (Hg.), Aelredi Rievallensis Opera Omnia 1 (Corpus Christianorum, Continuatio Medievalis 1). Turnhout 1971, S. 99-101. 
Abb. 3: Clairvaux, vetus monasterium, Grundriß (a) und Ansicht von Westen (b) (Milley 1708), aus: Studies in Cistercian art and ArchitectureI(1982), S. 6-7.
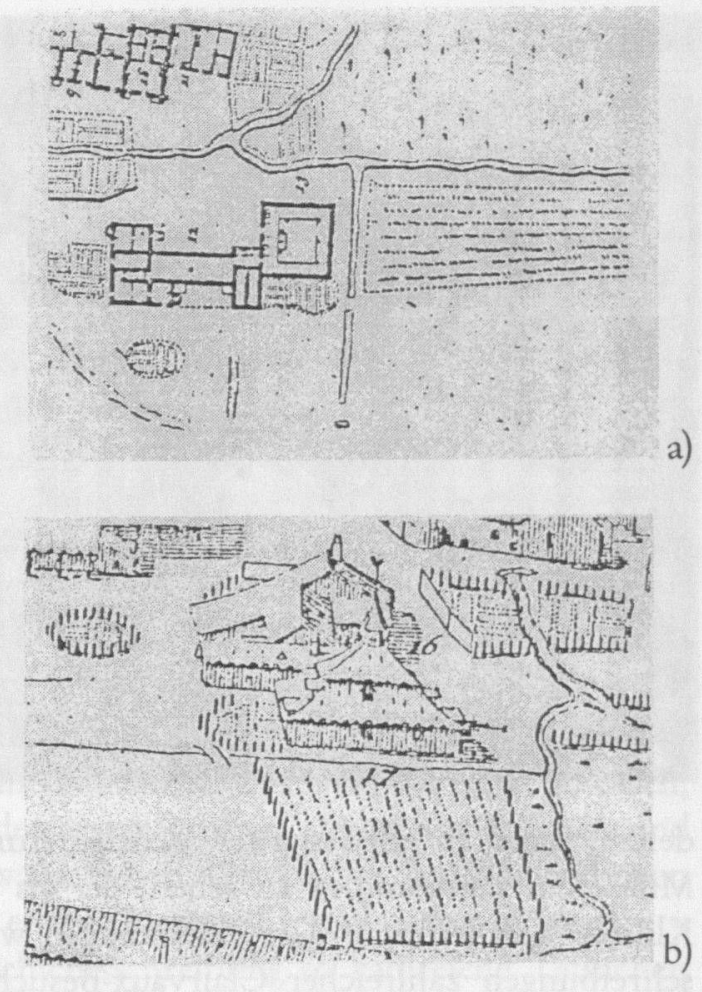

\section{BERNHARD VON CLAIRVAUX ALS BAUHERR}

Es ist unbestrittenes Handbuchwissen, daß sich Bernhard von Clairvaux eigentlich nicht für das Bauwesen interessiert hat und daß die monumentale Zisterzienserbaukunst erst in den Jahren um 1135 beginnt, nämlich mit dem von Bernhard zunächst abgelehnten Bau der ersten steinernen Kirche von Clairvaux - beides ist, wie ich meine, unzutreffend. Man kann dies mit der Baugeschichte von Clairvaux begründen.

Die Baugestalt des ersten, 1114 von Abt Bernhard und seinen Mönchen bezogenen Klosters ist nämlich recht gut bekannt, auch wenn die Amerikanerin Jean Schaefer erst 1982 diese Tatsache ins Gedächtnis zurückgerufen hat ${ }^{41}$ - und ihre Wiederentdeckung bis heute wenig beachtet wird. Westlich der großen Klosteranlage ist auf den 1708 entstan-

41 Jean Owens Schaefer, The Earliest Churches of the Cistercian Order, in: Meredith Parsons Lillich (Hg.), Studies in Cistercian Art and Architecture 1 (Cistercian Studies Series 66). Kalamazoo 1982, S. 1-12. 


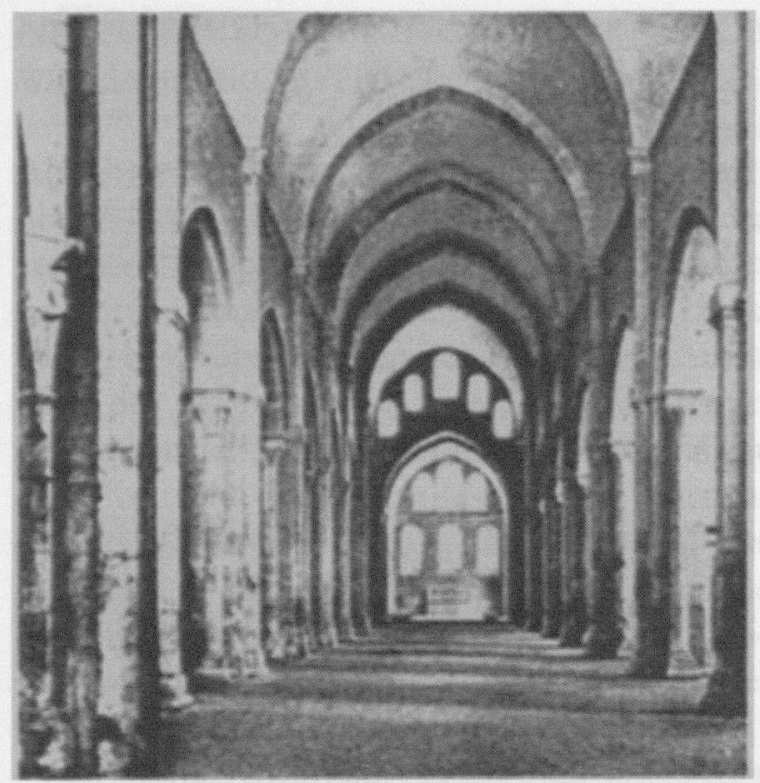

Abb. 4: Fontenay, Langhaus nach Osten, aus: L'Art Cistercien I. Zodiaque, La nuit des temps, Tafel 3.

denen, meist in allzu starker Verkleinerung abgebildeten Stichen von Milley ein Baukomplex zu sehen, der als vetus monasterium, als „altes Kloster" galt (Abb. 3). Die Zeichnungen werden durch ausführliche Beschreibungen zahlreicher Clairvaux-Besucher des 16. bis 18. Jahrhunderts erläutert. ${ }^{42}$ Es handelte sich um eine hölzerne Stabkirche mit etwa quadratischem Mittelraum, der das Chorgestühl und den Hauptaltar aufnahm, sowie zwei Nebenaltären im Umgang. Das Holzgebäude daneben nahm in seinem Erdgeschoß das Refektorium und die Küche auf, im Obergeschoß das Dormitorium und die Zelle Bernhards; ein Kreuzgang fehlte. Mehr war im Jahr 1114 offenbar nicht notwendig, um ein regeltreues zisterziensisches Klosterleben führen zu können.

Nach Aussage der ältesten zisterziensischen Generalkapitelsstatuten von etwa 1123/24 mußten folgende Bauten eines Klosters vor Ankunft eines neuen Konvents bezugsfertig $\operatorname{sein}^{43}$ : oratorium, refectorium, dormitorium, cella hospitum und cella portarii - also Kirche, Speise- und Schlaf-

42 Besonders wichtig: Voiage de la Royne de Secile, 1517: Henri Michelant, Un grand monastère au XVIe siècle, in: Annales archéologiques 3 (1845), S. 223-259, hier S. 236-237; Joseph Meglinger, Descriptio itineris Cisterciensis ... mense Maio anni 1667, cap. 57, Luzern o. J. (ca. 1670), wiederabgedruckt in Migne PL 185, Sp. 1600.

43 Capitula („von 1123/24“), cap. 9: Bouton / van Damme, Anciens textes de Cîteaux, 1974, S. 121; de Place, Cîteaux. Documents primitivs, 1988, S. 126-127. 
raum, Herberge für die Laien und Pfortenhaus. Genau diese Räume sind in Clairvaux vorhanden - Pforte und cella bospitum gehören natürlich an die äußere Grenze des Klosterbezirks, Küche und Vorratsräume sind eine Selbstverständlichkeit und werden nicht genannt. Schriftüberlieferung und Bautyp entsprechen einander.

Es gibt keinen Grund, an der klösterlichen Tradition zu zweifeln: Dieses Kleinkloster entstammt der Frühzeit von Clairvaux. Es wurde als Kontaktreliquie des hl. Bernhard bis in die Barockzeit hinein bewahrt und ist erst dem Bau eines Prunkgartens zum Opfer gefallen.

Galten der ersten Generation der Zisterziensermönche gerade solche Kleinklöster als angemessene Lebens- und Arbeitsumgebung? Spiegeln sich hier die Ideale einer neuen monastischen Bewegung? Verweigerten sich die fundamentalistischen Reformer mittelalterlichen Mönchslebens dem Bau konventioneller, vielräumiger Klosterbauten, wo allein schon die Probleme der Finanzierung die gewünschte Abkehr von der Welt zur Illusion werden ließen?

Erstaunlicherweise läßt uns die schriftliche Überlieferung im Stich, wenn wir nach der Bauzeit der ersten großen, steinernen Kirchen und Klöster in Cîteaux und Clairvaux fragen. Gerade bei den Primarabteien erfahren wir nicht, wann die ersten, kleinen Klöster verlassen wurden obwohl die frühe Ordensgeschichtsschreibung so zahlreiche Tatsachen und Episoden überliefert. Man hat diese Großbauten schon im 12. Jahrhundert als „Sündenfall“ empfunden, als eine Entwicklung, die den Zisterzienserorden nicht nur wegführte von seinen alten Idealen, sondern dies auch noch vor aller Augen deutlich machte. ${ }^{44}$

Für die bildlich überlieferte große Klosterkirche von Clairvaux gibt es viele Baudaten ${ }^{45}$ : Mit dem Bau war in den Jahren um 1148 begonnen

44 Petrus Cantor, Verbum abbreviatum (von 1191/92), cap. 86: ediert ist nur die kürzere Version des Textes: Migne PL 205, 23-370, hier 255 B-259 D; ausführlicher Text auszugsweise bei; John W. Baldwin, Masters, Princes and Merchands. The Social View of Peter the Chanter and his Circle, 2 Bde. Princeton 1970. Hier Bd. II, S. 183 n. 28.; vgl. ebd. Bd. I, S. 66-70 mit Anm. 19-36.

45 Zum Folgenden: Paul Jeulin, Les tranformations topographiques et architecturales de l'abbaye de Clairvaux, in: Mélanges Saint Bernard. XXIVe congrès de l'Association Bourguignonne des Sociétés Savantes Dijon 1953. Dijon 1954, S. 325-341 (mit Quellen- und Literaturverzeichnis); Ders., Quelques découvertes et constatations faites à Clairvaux depuis une vingtaine d'années, in: Bulletin de la Société Nationale des Antiquaires de France (1960), S. 94-118; Wilhelm Schlink, Zwischen Cluny und Clairvaux (Beiträge zur Kunstgeschichte 4). Berlin 1970, S. 91, 108-116, 138-141; Terryl N. Kinder: Les églises médiévales de Clairvaux. 
worden; 1153 wurde Bernhard vor dem Hochaltar beigesetzt, geweiht wurde sie 1178. Beim Tod Bernhards sollen über 500 Mönche gleichzeitig in Clairvaux gelebt haben. Man muß diese Zahl nicht wörtlich nehmen. In die gleiche Größenordnung zielt Conrad von Eberbach, der im "Exordium magnum" berichtete, daß um 1145 in Clairvaux 90 bis 100 Novizen gleichzeitig das Noviziat abgeleistet hätten. ${ }^{46}$

Erstaunlicherweise schweigen die Biographen Bernhards über die Bauten, die vor dieser bildlich faßbaren frühgotischen Klosteranlage in Clairvaux bestanden haben. Die bekannte Episode seiner Vita, daß sich Bernhard einer Klosterverlegung und einem Neubau zunächst widersetzte, ist chronologisch sicherlich falsch eingeordnet, nämlich auf 1135 dies hat man schon bei der zweiten Redaktion im 12. Jahrhundert bemerkt. ${ }^{47}$ Bernhard erwähnt in seinem Plädoyer nämlich nicht nur die bekannten, aufwendigen Wasserleitungen, sondern auch aufwendige Steingebäude und eine hochaufragende Kirche - und genau diese Satzteile fehlen in der letzten Textfassung. Die Verlegungsdebatte gehört also erst zum zweiten Neubau von 1148; der oft genannte Baubeginn einer ersten großen Kirche von 1133 oder 1135 ist eine Fiktion der Forschung.

Aus den Notizen von Bernhards Sekretär Gottfried ist demgegenüber eine große Kirchenweihe schon vor $1130 \mathrm{zu}$ erschließen. ${ }^{48}$ Als Papst Innozenz II. mit seinem Hofstaat 1131 in Clairvaux war, muß er schon das neue, große Kloster gesehen haben. ${ }^{49}$

Wie lange hat das erste Holzkloster den Konvent von Clairvaux beherbergt? Die ältere Forschung nahm an, daß der Konvent bis 1135 dort gelebt habe; allerdings hat man sich über Bauform und Größe keine rechten Gedanken gemacht. Diese Annahme erübrigt sich bei der genauen Betrachtung des Holzklosters und seiner Größe: Seit 1115 hatte Clairvaux eine Vielzahl von Mönchen aufgenommen; bis 1135 waren schon 19 Tochterkonvente mit rund 250 Mönchen und ungezählten

Probabilites et fiction, in: Histoire de Clairvaux, Actes du colloque de Bar-surAube/Clairvaux, 22 et 23 juin 1990. o.O. 1991, S. 204-229.

46 Conrad von Eberbach, Exordium magnum VI 10: Bruno Griesser (Hg.), Exordium magnum Cisterciense sive Narratio de initio Cisterciensis ordinis, auctore Conrado (Series Scriptorum S. Ordinis Cisterciensis 2). Rom 1961, S. 366.

47 Arnold von Bonneval, Vita Bernardi prima II 5: Migne PL 185, Sp. 284 D-285 D. - Dazu Bredero, La "Vita prima“ de Saint Bernard, 1961, S. 254 Anm. 5, S. 257 Anm. 2.

48 Gottfried von Auxerre, Fragmenta 37: Robert Lechat, Les Fragmenta de Vita et Miraculis S. Bernardi par Geoffroy d'Auxerre, in: Analecta Bollandiana 50 (1932), S. 83-122, hier S. 109.

49 Arnold von Bonneval, Vita Bernardi prima II 1; Migne PL 185, Sp. 272. 
Konversen gegründet worden. Im Dormitorium des ersten Klosters hatten sicherlich nur wenig mehr als die ersten zwölf Mönche mitsamt einigen Konversen Platz gefunden, ebenso im Chorgestühl der winzigen Kirche - der Mittelraum war knapp fünf mal sechs Meter groß. Man wird die Bereitschaft mittelalterlicher Mönche zu improvisieren nicht überschätzen dürfen: Gerade beim Wohnen auf engem Raum und beim Chorgebet war es undenkbar, zu viele Menschen zusammenzudrängen, ohne die strenge Ordnung des regelgemäßen Ordenslebens zu gefährden.

Für Clairvaux und Cîteaux kommt also nur ein Schluß in Frage: Große Kirchen- und Klosterbauten müssen schon beim ersten Aufblühen des Ordens um 1120 begonnen und dann rasch fertiggestellt worden sein - in der gleichen Zeit also, als die päpstliche Sicherung der Ordensverfassung und der Zehntfreiheit erlangt war, als der Orden sich durch Filiation weit auszudehnen begann und sich in Generalkapitel und Statuten seine Struktur gab.

Die von mir vorgeschlagene frühe Datierung zisterziensischer Monumentalbaukunst ist in verschiedener Hinsicht plausibel. Die Forschung konnte bislang nicht erklären, warum Bernhard sich um 1124 so intensiv mit Kirchen- und Klosterbaukunst auseinandergesetzt hat nämlich in seiner Apologie -, wenn er damals noch gar keine Bauabsichten gehabt haben soll und angeblich erst ein Dutzend Jahre später in seinem eigenen Kloster einen Neubau begann. Die Apologie hat ihren historischen Ort tatsächlich im Kontext der großangelegten Neubauten von Clairvaux und Cîteaux - Bernhard mußte nicht nur theoretisch Stellung beziehen zu den Kirchenanlagen und Klosterbauten der Cluniazenser. Außerdem kennen wir inzwischen eine ganze Reihe von großen steinernen Kirchenbauten der Zisterzienser aus der Zeit um 1125/30. Deren Existenz wäre schwer verständlich zu machen, wenn damals in Cîteaux und Clairvaux noch keine „normalgroßen“ Klosteranlagen existiert hätten. Hier sei nur die ergrabene erste Kirche und Klausur von Walkenried im Harz genannt, die 1129 begonnen und schon 1137 geweiht wurde..$^{50}$ Bernhard war also schon um 1120 Bauherr eines großen, steinernen Klosters - und 1148 begann er einen zweiten, noch größeren Bau.

50 Bernd Nicolai, Walkenried. Anmerkungen zum Forschungsstand, in: Niederdeutsche Beiträge zur Kunstgeschichte 28 (1989), S. 9-32. 


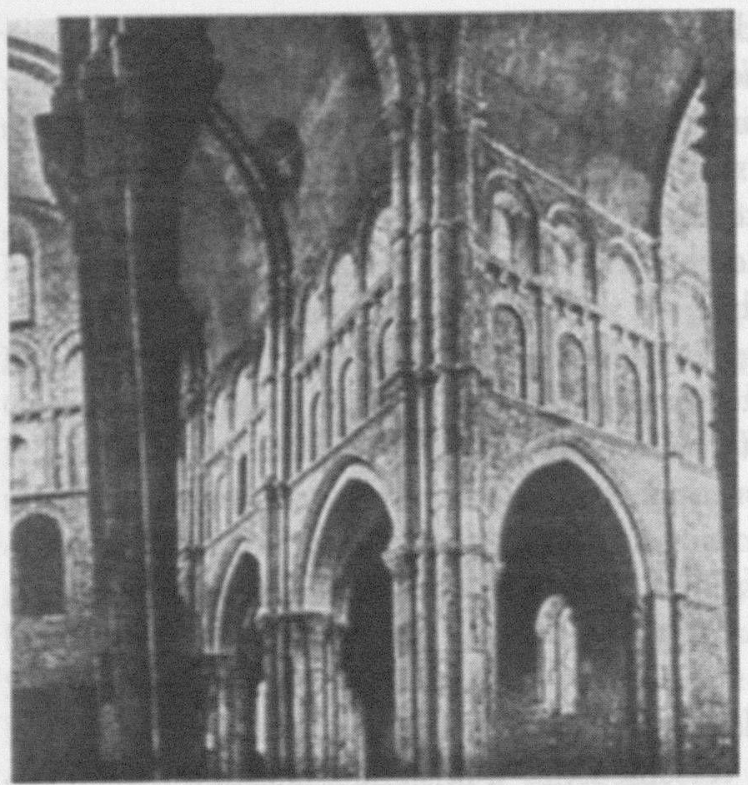

Abb. 5: Paray-le-Monial, Nordquerarm und Langhaus, aus: Bourgogne Romane. Zodiaque, La nuit des temps, 3. Aufl., Tafel 3.

\section{ZISTERZIENSERARCHITEKTUR ALS ZITAT}

Als Spiegel der ersten, nicht bekannten Kirche von Clairvaux gilt die nahe Abtei Fontenay (Abb. 4). Ihre Bauformen zeigen keineswegs äußerste Armut $^{51}$, weder im aufwendigen Quaderwerk der Mauern noch im Schmuck der Kapitelle. Diese sind zwar nicht so reich ausgestaltet wie an zeitgleichen Benediktinerbauten, präsentieren sich aber auch nicht völlig schmuckfeindlich. Die Gliederung des Mittelschiffs ist zweigeschossig; unten gibt es rechteckige Pfeilervorlagen, darauf stehen Halbsäulen. Das ist eine architektonisch durchaus anspruchsvolle Gestaltung.

Ganz offensichtlich haben die Zisterzienser in Fontenay nicht beabsichtigt, eine möglichst billige, dabei aber große Kirche zu bauen. Das hätte auch um 1130 in Frankreich anders ausgesehen: einfaches Bruchsteinmauerwerk, ungegliederte Wänden, keine Gewölbe. Gleichzeitig präsentiert sich die Kirche aber ganz anders als normale Klosterkirchen und das ist offenbar Absicht.

51 Lucien Bégulé, L'abbaye de Fontenay et l'architecture cistercienne. Lyon 1912 (in Quart!); zitiert und benutzt findet man normalerweise den leichter erreichbaren Kurzführer gleichen Titels, der mehrere Auflagen erlebt hat. Vgl. auch Denis Cailleaux, La restauration de l'abbaye de Fontenay (1906-1911), in: Bulletin archéologique Nouvelle série 19 (1983), S. 69-95. 


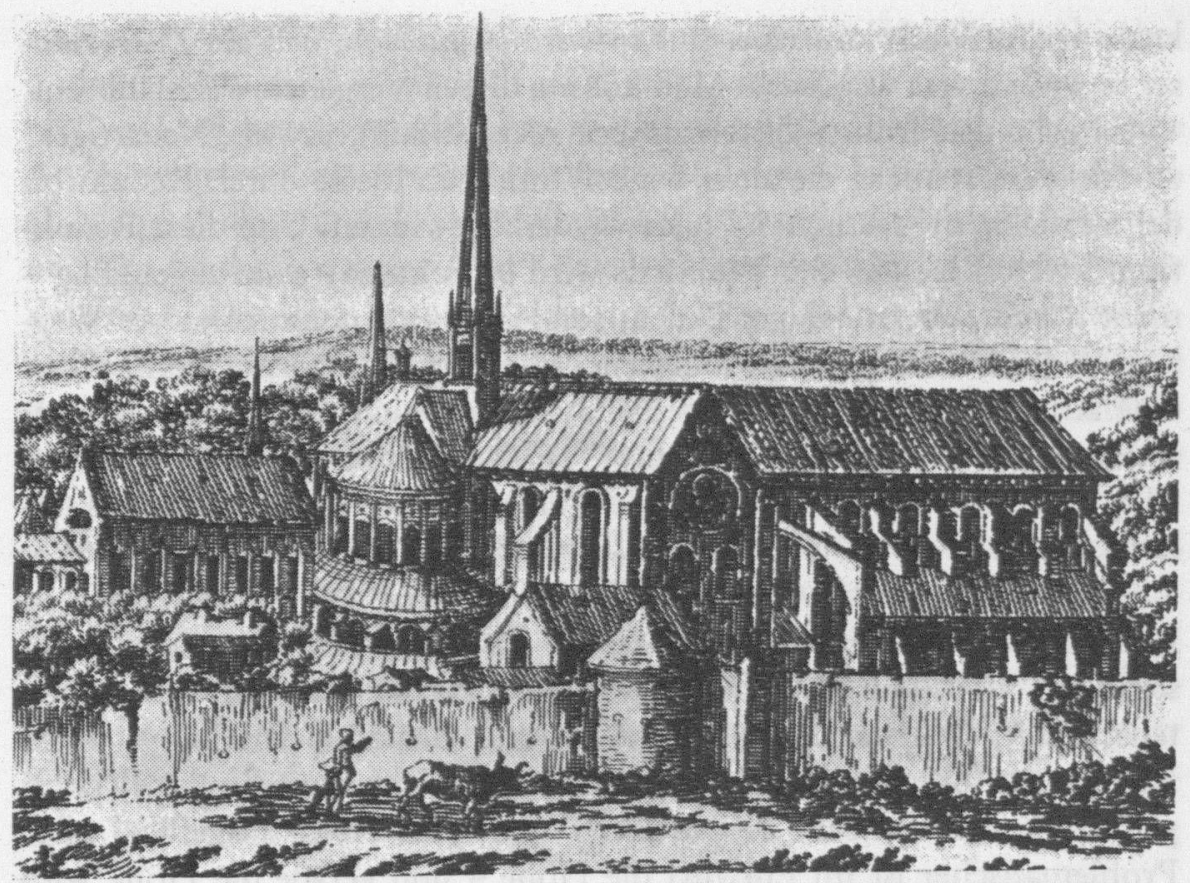

Abb. 6: Clairvaux, Bau III von Nordosten (Silvestre, 17. Jh.), aus: Scblink, Von Cluny nach Clairvaux 1970, Abb. 97.

Sie zitiert bewußt den in Burgund von Cluny ausgehenden Standard für große Klosterkirchen, der sogar die bischöfliche Baukunst geprägt hat. ${ }^{52}$ Im Vergleich mit Paray-le-Monial (Abb. 5) fallen nicht nur Unterschiede, sondern auch Übereinstimmungen auf. Fangen wir unten an: Die Arkaden sind spitzbogig und gestuft, die Pfeiler haben eine rechtekkige Vorlage, auf der eine Halbsäule steht - soweit ist es gleich. Nun wird es anders: Über den Arkaden folgt ein Band mit reich dekorierten Blendbögen, dann folgen die Mittelschiff-Fenster im Obergaden. Nun, wiederum übereinstimmend, kommt das Tonnengewölbe, das von Gurtbögen in schmale Streifen geteilt ist. In Fontenay hat man auf die beiden „reichdekorierten“ Zonen verzichtet und das Gewölbe unmittelbar auf die Arkaden gesetzt, und zwar ganz demonstrativ, unter Verzicht auf Mittelschiff-Fenster. Man hätte auch die Arkaden selbst weglassen können, denn die Seitenschiffe haben in einer Zisterzienserkirche gar

52 Mit anderen Akzenten: Pierre Gilbert, Un chef-d'œuvre d'art cistercien peut-être influencé par Cluny, l'abbatiale de Fontenay, in: Bulletin de la Classe des BeauxArts (Académie royale de Belgique) 52 (1970), S. 20-45. 
keine rechte Funktion. Aber nur so wird ja deutlich, daß die Zisterzienser bewußt etwas weglassen. Man könnte diesen Vergleich weiterführen.

Es geht den frühen Zisterziensern nicht darum, etwas "Neuartiges“ zu schaffen, sondern die alten benediktinischen Ideale durch Reduktion der aktuellen monastischen Praxis wiederzugewinnen. Und diese Reduktion der cluniazensischen Baupraxis wird in Fontenay ganz augenfällig nicht durch äußerst billiges Bauen, sondern durch demonstratives Weglassen reicher Formen. Eine amerikanische Wirtschaftshistorikerin hat es eine zisterziensische Eigenart genannt, daß sie nicht die Armut suchen, sondern den "Anschein von Armut ${ }^{\alpha 33}$. Man sollte aus dieser Formulierung nicht den Vorwurf der Doppelmoral oder der Unlauterkeit herauslesen.

Große Mönchskonvente brauchen große Kirchen und, wie man in Fontenay deutlich sieht, große Klöster. Zisterzienserkirchen haben, das stand gar nicht zur Debatte, angemessene, sakrale Bauformen: mit Seitenschiffen, Querschiff, Arkadenbögen und Gewölbe. Die Länge dieser Kirchen ist, um mit Bernhard zu sprechen, nicht unmäßig, weil sie ja ganz vom Chorgestühl der Mönche und Konversen ausgefüllt wird. Problematischer ist im Entwurf die Höhe - und gerade die Höhe wird reduziert. Und nicht nur die Höhe, sondern auch der überflüssige Reichtum der Wandgestaltung. Es ist bezeichnend, daß der Betrachter durch Zitate - nämlich die Spitzbögen, die zweigeschossige Wandgliederung und die Quergurte des Tonnengewölbes - bewußt zum Vergleich mit Cluny aufgefordert wird - und dann den zisterziensischen Verzicht klar erkennt.

Im Grundriß geht es noch weiter (Abb. 7 u. 8). Hier hat das zisterziensische Streben nach rectitudo und simplicitas unmittelbaren architektonischen Ausdruck gefunden: Richtigkeit und Geradlinigkeit bilden seit dem Auszug aus Molesme zisterziensische Prinzipien der Lebensführung und Regelauslegung ${ }^{54}$ - geradlinige Grundrisse setzen sich ebenso deutlich von cluniazensischen Bauten ab. Wenn Villard de Honnecourt den Strichplan einer Zisterzienserkirche als desquarie, also als „eckig“ be-

53 Constance H. Berman, The Development of Cistercian Economic Practice During the Lifetime of Bernard of Clairvaux: The Historical Perspective on Innocent II's privilege, in: Cîteaux 42 (1991), S. 303-313.

$54 \mathrm{Pia}$ Schindele, Rectitudo und Puritas, in: Clemens Kasper / Klaus Schreiner $(\mathrm{Hg}$.), Zisterziensische Spiritualität (Studien und Mitteilungen zur Geschichte des Benediktinerordens und seiner Zweige, Ergänzungsband 34). St. Ottilien 1994, S. 53-72. 
zeichnet (Abb. 2) ${ }^{55}$, hat er die Gleichsetzung von moralisch-ethischer und architektonischer rectitudo nicht mehr verstanden.

Der 1148 begonnene Neubau der Kirche von Clairvaux erhielt eine Apsis, einen säulengetragenen Umgang und einen Kapellenkranz (Abb. 6). Man hat dies oft als Sündenfall der Zisterzienserarchitektur angesehen und den Baubeginn sogar - der Ordenstradition widersprechend - in die Zeit nach dem Tod Bernhards datiert. ${ }^{56}$ Doch auch diese Bauform bezieht sich durch erkennbar vereinfachendes Zitieren auf die zeitgleiche Benediktinerbaukunst: Als Parallele sei hier nur auf den kaum älteren neuen Ostbau von St.-Denis hingewiesen mit den ebenfalls dicht gereihten Umgangskapellen, die allerdings außen jeweils als Apsis hervortreten - zu nennen wären auch die neuen Ostbauten von St.-Germain-des-Près in Paris und Vézélay. ${ }^{57}$ Diese benediktinische Bauform wurde von spanischen und anglonormannischen Zisterzienserkirchen rasch aufgegriffen.

Im Zisterzienserorden entstand bekanntlich schon bald eine charakteristische rechteckige Umformung - am 1147 vorbereiteten, aber später begonnenen Ostbau von Cîteaux, der dann über Morimond weite Nachfolge fand, besonders im deutschen Reich. ${ }^{58}$

55 Hahnloser, Villard de Honnecourt, 1972), S. 65-67, 355-356, Tafel $28 \mathrm{~b}$.

56 Zur Datierung vgl. oben S. 251.

57 Knappe Bemerkungen zu dieser Bautengruppe: Bernd Nicolai, „Libido aedificandi“. Walkenried und die monumentale Kirchenbaukunst der Zisterzienser um 1200 (Quellen und Forschungen zur Braunschweigischen Geschichte 28). Braunschweig 1990, S. 89, 91; mit ganz anderen Schwerpunkten: Mario Kramp, Kirche, Kunst und Königsbild. Zum Zusammenhang von Politik und Kirchenbau im capetingischen Frankreich des 12. Jahrhunderts am Beispiel der drei Abteien Saint-Denis, Saint-Germain-des-Prés und Saint-Remi/Reims. Weimar 1995, besonders S. 114-116.

58 Nicolai, „Libido aedificandi“; vgl. Ders., Lilienfeld und Walkenried. Zur Genese und Bedeutung eines zisterziensischen Bautyps, in: Wiener Jahrbuch für Kunstgeschichte 41 (1988), S. 23-39, 163-172. 


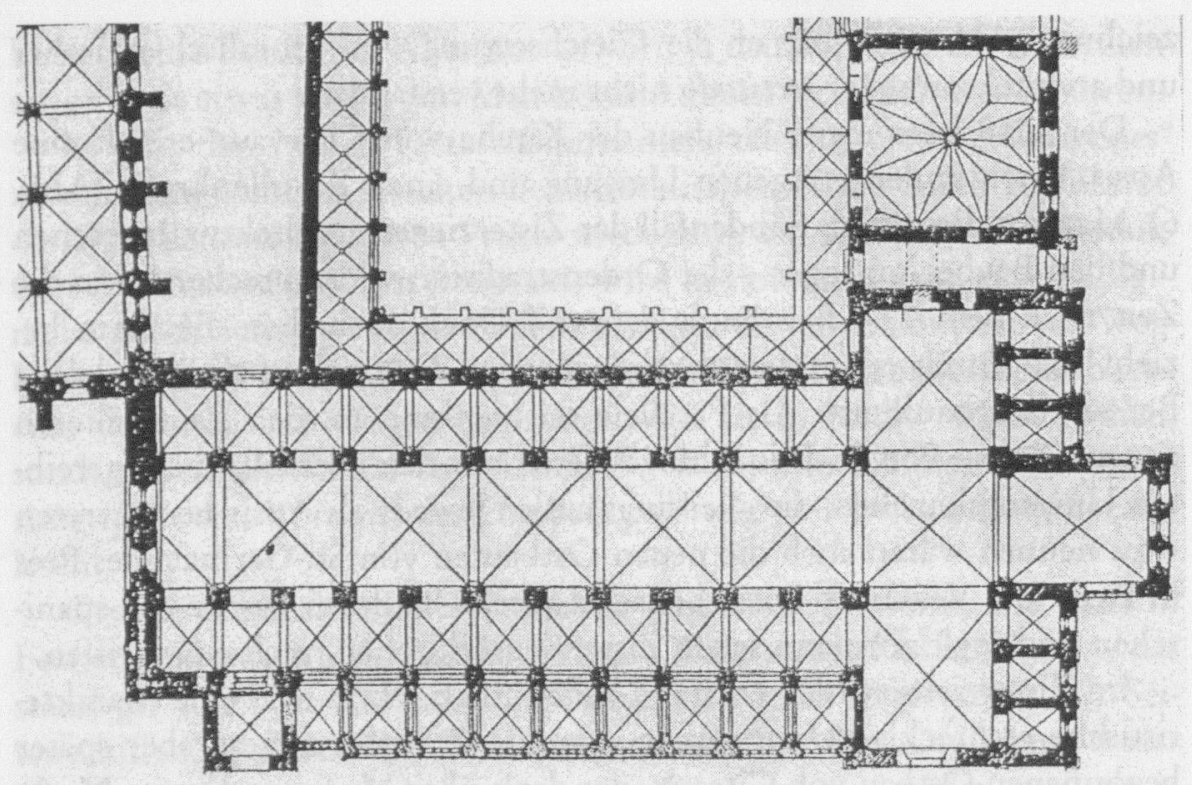

Abb 7: Eberbach, Grundriß aus H. Habn, Kirchenbaukunst der Zisterzienser 1957, Textabb. 1 (Ausschnitt Kirche).

\section{EINHEITLICHKEIT DER ARCHITEKTUR ALS GARANT DER EINHEIT DES ORDENS}

Abschließend sollen noch die Gründe für die Einheitlichkeit der zisterziensischen Bautypen und für die auffallende Traditionsbildung dieser "Ordensbaukunst“ angesprochen werden. Grundsätzlich muß man festhalten, daß es nicht einen Traditionsstrang gibt, sondern mehrere. „Einheitlichkeit“ stand nicht am Anfang, sondern wird erst im Laufe des 12. Jahrhunderts faßbar. Viele Bauten, die unser Bild der Zisterzienserarchitektur prägen, gehören dem späten 12., oft sogar dem 13. Jahrhundert an.

Stellvertretend mögen hier Eberbach im Rheingau und Fossanova in Latium genannt sein (Abb. 7 - 10). ${ }^{59}$ Beide präsentieren den gleichen

59 Hahn, Frühe Kirchenbaukunst; zu Fossanova auch: Lelia Fraccaro de Longhi, L'architettura delle chiese cistercensi italiane. Mailand 1958, S. 235-241; und immer noch Georg Dehio, Zwei Zisterzienserkirchen, Pontigny und Fossanova, in: Jahrbuch der Königlich Preussischen Kunstsammlungen 12 (1891), S. 91-103; Camille Enlart, Origines françaises de l'architecture gothique en Italie (Bibliothèque des Écoles françaises d'Athènes et de Rome 66). Paris 1894, S. 33-39. 


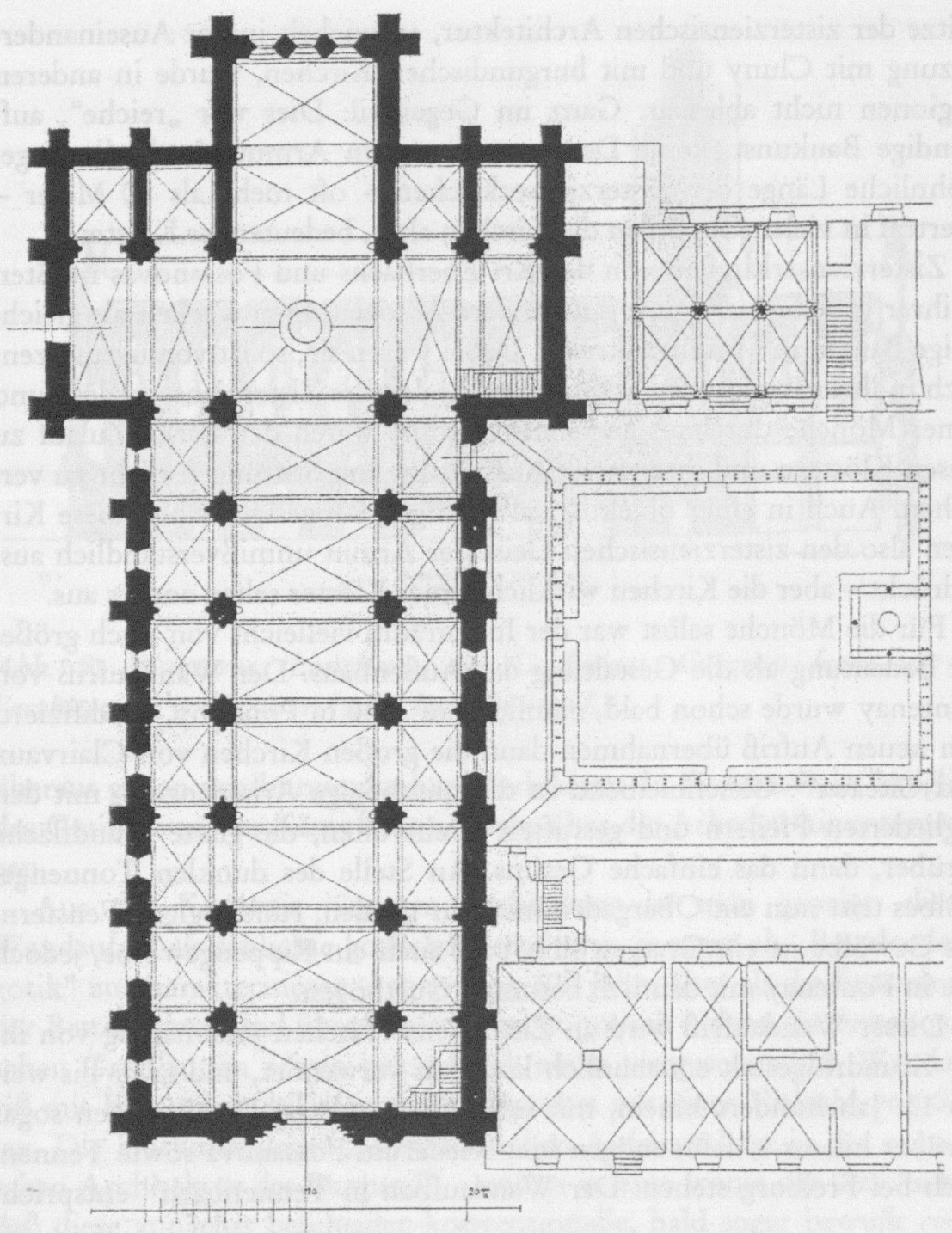

Fig. 5. Fossanoya

Abb. 8: Fossanova, Grundriß aus: G. Dehio, in: Jahrb. Preuss. Kunstsammlungen 1891, S. 99.

Bautyp, eine Modernisierung der Bauform von Fontenay. Im deutschen Reich war eine Kirche ohne Apsiden aber gar nicht so ungewöhnlich wie im Burgund; in Italien wiederum stellte eine vollständig gewölbte Kirchen wie Fossanova eine Sensation dar. Die asketisch-reformerische 
Spitze der zisterziensischen Architektur, entwickelt in der Auseinandersetzung mit Cluny und mit burgundischen Kirchen, wurde in anderen Regionen nicht ablesbar. Ganz im Gegenteil: Dies war „reiche“, aufwendige Baukunst, keine Demonstration von Armut. Auch die ungewöhnliche Länge der Zisterzienserkirchen - oft mehr als 80 Meter übertraf in vielen Gegenden die Kirchen alter, bedeutender Klöster.

Zisterzienserkirchen von der Art Eberbachs und Fossanovas mußten in ihrer jeweiligen Region ganz andere Assoziationen wecken als gleichartige Bauten in Mittelfrankreich. Dabei waren sie, so ist vorauszusetzen, auch in ihrer Region den asketischen Idealen des Zisterzienserordens und seiner Mönche durchaus angemessen, sonst wären der starke Zulauf zu diesen Klöstern und ihre reiche Ausstattung mit Stiftungen nicht zu verstehen. Auch in einer objektiv aufwendigen Baugestalt haben diese Kirchen also den zisterziensischen Geist der Armut unmißverständlich ausgedrückt - aber die Kirchen wirklich armer Klöster sehen anders aus.

Für die Mönche selbst war der Innenraum vielleicht von noch größerer Bedeutung als die Gestaltung des Außenbaus. Der Wandaufriß von Fontenay wurde schon bald, nämlich um 1130 in Pontigny, modifiziert; den neuen Aufriß übernahmen dann die großen Kirchen von Clairvaux und Cîteaux ${ }^{60}$ : Gleichbleibend ist die spitzbogige Arkadenzone mit den gegliederten Pfeilern und gestuften Archivolten, die glatte Wandfläche darüber, dann das einfache Gesims. An Stelle des dunklen Tonnengewölbes tritt nun ein Obergaden mit sehr großen, rundbogigen Fenstern; das Gewölbe ist ein Gratgewölbe, bald auch ein Rippengewölbe, jedoch wie in Fontenay mit deutlich betonten Gurtbögen.

Dieser Wandaufriß wird an Zisterzienserkirchen unabhängig von ihrer Grundrißgestalt entstaunlich konstant verwendet, und zwar bis weit ins 13. Jahrhundert hinein, mit erkennbar anderen Detailformen sogar darüber hinaus - dafür mögen hier wiederum Fossanova sowie Tennenbach bei Freiburg stehen. Der Wandaufbau in Tennenbach ${ }^{61}$ entspricht

60 Robert Branner, Burgundian Gothic Architecture (Studies in Architecture 3). London 1960, S. 16-17; Zur Datierung: Terryl N. Kinder, The Original Chevet of Pontigny's Church, in: Meredith Parsons Lillich $(\mathrm{Hg}$.), Studies in Cistercian Art and Architectur 2 (Cistercian Studies Series 69). Kalamazoo 1984, S. 30-38; Dies., Toward Dating Construction of the Abbey Church of Pontigny, in: Journal of the British Archaeological Association 145 (1992), S. 77-88. - Zu Clairvaux vgl. Kinder, Clairvaux, in: Histoire de Clairvaux, 1991, S. 204-229; Michael Miguet, La demolition de l'église de Clairvaux, ebd. S. 231-242, hier S. 234-235.

61 Ernst-Friedrich Majer-Kym, Die Bauten der Cistercienser-Abtei Tennenbach, Bd. I: Die Klosterkirche, in: Oberrheinische Kunst 2 (1926/27), S. 87-116. 


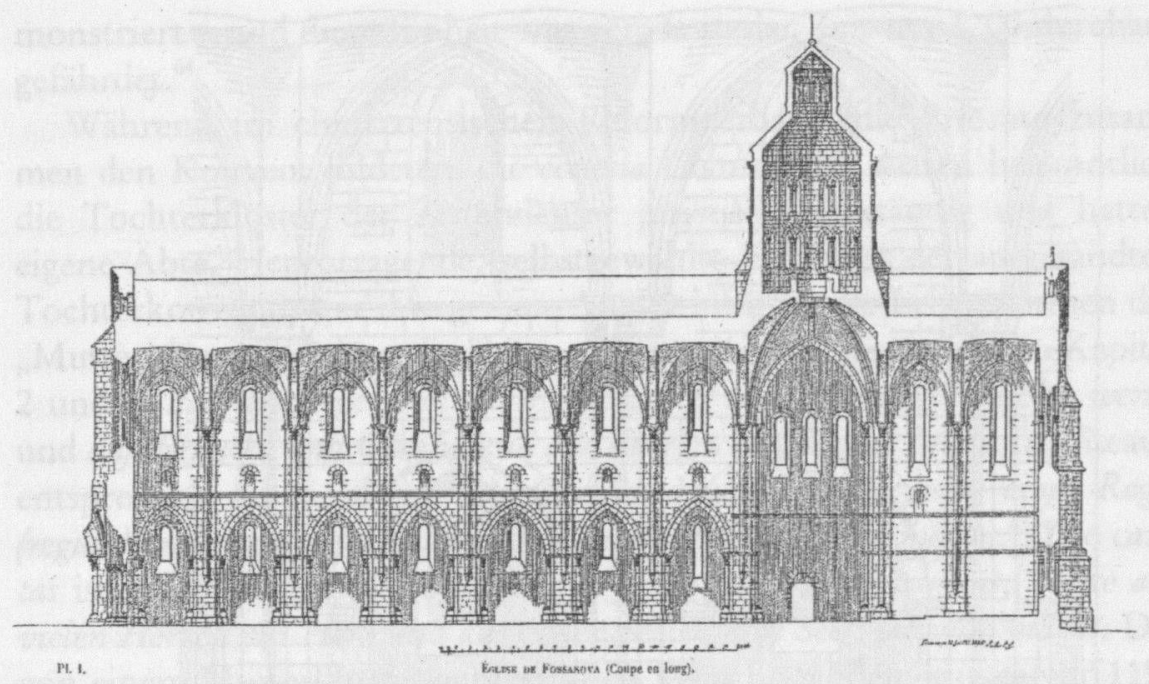

Abb. 9: Fossanova, Langhaus, aus C. Enlart, Origines françaises de l'architecture gotbique en Italie, Paris 1894, PL1.

überaus genau den burgundischen Vorbildern. In Fossanova ist lediglich das Gesims von der Kämpferzone dicht über die Arkaden hinuntergezogen.

Aus der Kenntnis jüngerer Architektur ist man geneigt, diesen Wandaufriß als schlichte gotische Gestaltung, ja sogar als „Bettelordensgotik“ zu charakterisieren - aber er ist 100 Jahre älter als die Entstehung der Bettelorden. Und überdies ist er nicht gotisch - denn die ersten gotischen Großbauten zeigen bekanntlich einen viergeschossigen Wandaufriß mit Empore und Triforium, ausgestaltet mit einer Vielzahl von Säulen. Die Herkunft dieses zisterziensischen Aufrisses liegt in der romanischen Architektur des Burgund ${ }^{62}$ - und es ist eine Ironie der Geschichte, daß diese zunächst bescheiden-konventionelle, bald sogar bewußt reduzierend- konservative, sich verweigernde Gestaltung nicht nur in den „mainstream“ der gotischen Architektur einmündete, sondern vielen Regionen den ersten Kontakt zur progressiven Architektur Frankreichs vermittelte. $^{63}$

62 Hans Rose, Die Baukunst der Cistercienser, München 1916; vgl. zu den südburgundischen Bauten Andreas Stürmer, Saint-Lazare zu Avallon (26. Veröffentlichung der Abteilung Architektur des Kunsthistorischen Instituts der Universität zu Köln). Köln 1984.

63 Dehio, Zisterzienserkirchen; Enlart, Origines françaises. 


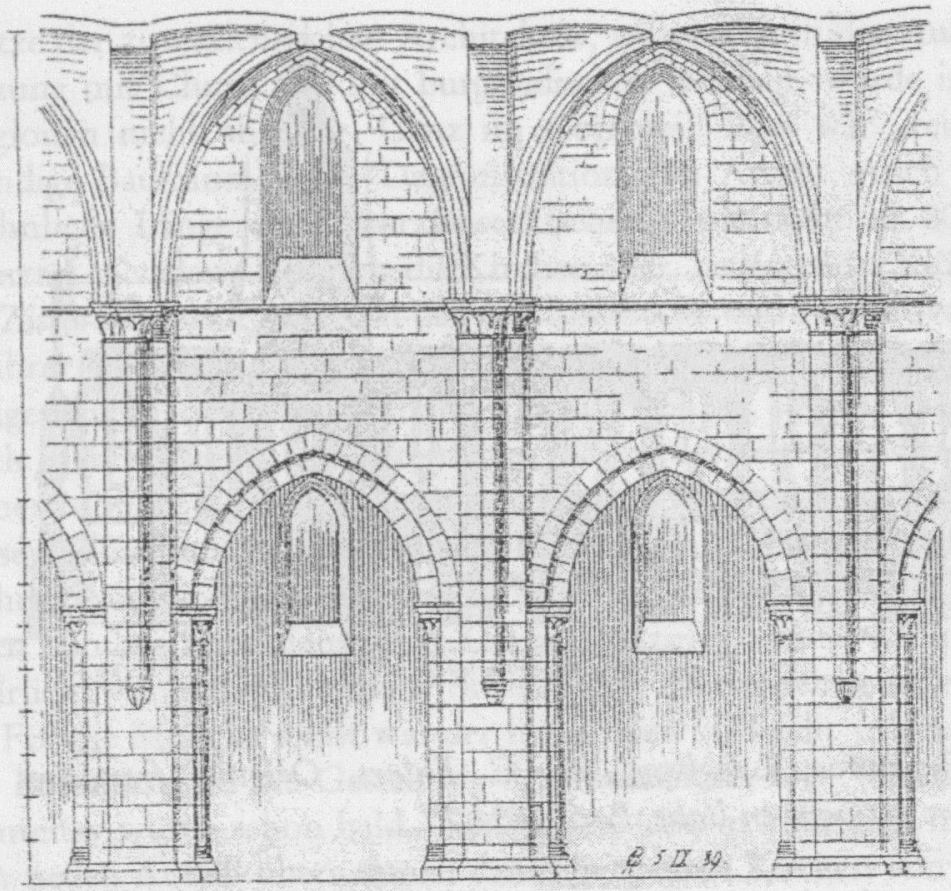

Abb. 10: Fossanova, Langhaus, aus: G. Dehio, in: Jabrb. Preuss. Kunstsammlungen 1891, Textabb. 1.

Ebensowenig wie bei den rechteckigen Grundrissen und den polygonalen oder rechteckigen Kapellenkränzen handelt es sich bei diesem Wandaufriß um den Ausdruck eines „zisterziensischen Stils“. Hier wird vielmehr eine architektonische Semantik faßbar, eine Formensprache. Die Elemente dieser Formensprache wurden im Burgund entwickelt und haben dort eine nachvollziehbare Bedeutung. Im deutschen Reich und in Italien war diese architektonische Sprache nicht in ihrem Inhalt verständlich. Ihre Bedeutung liegt vielmehr darin, daß sie die Einheit des Zisterzienserordens sichert - ebenso wie die Verwendung des Lateinischen die Einheit der Gesamtkirche gesichert hat. Und ebensowenig wie beim Kirchenlatein war es für den Laien, hier also für den Betrachter notwendig, die einzelnen Worte in ihrer eigentlichen Bedeutung zu erfassen. Die überregionale Bedeutung der zisterziensischen Formensprache bestand nicht darin, daß sie Askese und Armut darstellt, sondern darin, daß sie die Einheit, genauer: die „Einheitlichkeit“ des Ordens de- 
monstriert - und diese Einheit war gerade in der Zeit um 1200 durchaus gefährdeg. $^{64}$

Während im cluniazensischen Reformverband alle Priorate zusammen den Konvent bildeten, die ecclesia Cluniacensis, waren bekanntlich die Tochterklöster der Zisterzienser juristisch selbständig und hatten eigene Äbte. Hervorragende, selbstgewählte Eigenheit der ausgesandten Tochterkonvente war ihre genaue Angleichung an die Lebensformen des „Mutterklosters . Schon die älteste „Carta caritatis“ bestimmte in Kapitel 2 und 3, daß die Regel von allen einbeitlich verstanden und befolgt werde und daß Bräuche und Gesang und alle liturgischen Bücher denen in Cîteaux entsprechen sollen, damit wir in einer Liebe (caritas), nach einer Regel (regula) und nach gleichartigen Gebräuchen (mores) leben mögen. ${ }^{65}$ Die caritas ist, wie Idung um 1150 ausführt ${ }^{66}$, die Mutter der unitas, da sie aus vielen Herzen ein Herz und aus vielen Seelen eine Seele (anima) macht. Die von einem Mutterkloster ausgesandten Mönche wollen, wie es vor 1158 für La Ferté formuliert wurde ${ }^{67}$, nur im Leib, nicht im Geist (anima) getrennt Gott dienen. Ziel der angestrebten einheitlichen Regelbefolgung ist die Einmütigkeit (unanimitas). Die Zisterzienser glichen sich damit ausdrücklich dem Ideal der christlichen Urgemeinde an, wie es die Apostelgeschichte (Apg. 4,32) formuliert: Die Menge der Gläubigen war ein Herz und eine Seele.

64 Bruno Griesser, Rainer von Fossanova und sein Brief an Abt Arnald von Citeaux (1203), in: Cistercienser-Chronik 60 (1953), S. 151-167; Brenda Bolton, Non ordo sed horror: Innocent III's Burgundian Dilemma, in: Pierre Guichard $(\mathrm{Hg}$ ), Papauté, monachisme et théories politiques (Collection d'histoire et d'archéologie médiévales 1). Lyon 1994, S. 645-652; in den gleichen Kontext gehören die Beobachtungen von Michael Oberweis, Die Interpolationen im Chronicon Urspergense (Münchener Beiträge zur Mediävistik und RenaissanceForschung 40). München 1990, S. 73-111.

65 Bouton / van Damme, Anciens textes de Cîteaux, 1974, S. 92; de Place, Cîteaux. Documents primitivs, 1988, S. 62-63; vgl. die Capitula ("von 1123/24“), c. 10: Bouton / van Damme, Anciens textes de Cîteaux, 1974, S. 122; de Place, Cîteaux. Documents primitivs, 1988, S. 128-129.

66 Idung von Prüfening, Dialogus duorum monachorum, II 37; Robert B. C. Huygens, Le moine Idung et ses deux ouvrages Argumentum super quatuor questionibus et Dialogus duorum monachorum (Biblioteca degli Studi medievali. 11). Spoleto 1980, S. 140; leichter greifbar ist diese Textedition in: Studi medievali, 3. ser 13,1 (1972), S. 291-470, dort S. 424.

67 Georges Duby, Recueil des pancartes de l'abbaye de La Ferté-sur-Grosne 11131178 (Publication des Annales de la Faculté des Lettres d'Aix-en-Provence, N. S. 3). Gap 1953, S. 41-42, Nr. 1. 
Die „Ähnlichkeit“ vieler Zisterzienserkirchen war also Ausdruck und Mittel monastischer Ziele - einer neuen, ungewöhnlichen Verfassung, die dem einzelnen Mönch mehr Heilsgewißheit geben konnte als die Lebensformen der „alten Orden“. Diese Ähnlichkeit ist nicht das Ergebnis von Bauvorschriften, sondern einer ebenso freiwilligen wie heilsnotwendigen Selbstorientierung der vom Mutterkloster räumlich getrennten Konvente.

Caritas, unitas, unanimitas sind Begriffe, die zum Verständnis der zisterziensischen Architektur notwendig sind. Nur die caritas, die Liebe, ermöglicht die wahre Schau Gottes ${ }^{68}$, und diese im Kloster gelebte caritas bestimmt bekanntlich seit frühester Zeit das "Grundgesetz" der Zisterzienser, das ja Carta caritatis et unanimitatis heißt und unter diesem Titel die Einheit des Ordens organisiert. ${ }^{69}$ Das Neue, Eigentümliche der Zisterzienserarchitektur ist also nicht die Befolgung von Bauvorschriften, sondern der Versuch, in einer architektonischen Formensprache die Einheit des Ordens und seiner Lebensformen zu sichern. Auch wenn das Ergebnis eine Einheit mit vielen parallelen Zweigen war, erhielten die Konvente die heilsnotwendige architektonische Umgebung, in der sie erkennbar nur im Leib, nicht im Geist getrennt, Gott dienen konnten.

68 Vgl. Otto Langer, Affekt und Ratio. Rationalitätskritische Aspekte in der Mystik Bernhards von Clairvaux, in: Kasper / Schreiner (Hg.), Zisterziensische Spiritualität, 1994, S. 33-52.

69 Der heute naheliegend erscheinende Begriff uniformitas erscheint erst spät in den Quellen; vgl. einen Generalkapitelsbeschluß von $1465 \mathrm{Nr}$. 11: Canivez, Statuta V, S. 171. 